\title{
Stigma of mental illness and attitudes towards seeking mental health services among undergraduates in a public university in Malaysia
}

\author{
Hong Sing Yee \\ University of Malaya \\ *E-mail: singyee.hong@hotmail.com
}

\begin{abstract}
Many people with mental illnesses have faced, or are facing the burdened impact the stigma has acted on them. Needless to say, mental health stigma held by society is playing its role as a barrier that prevents many people from actively seeking professional mental help (Corrigan, 2004). Researcher then sought to examine the current level of stigma. Aims: To investigate whether the level of stigma surrounding mental illness is significant and whether it affects their attitude towards seeking mental help significantly. Methods: Questionnaires were distributed to 100 participants from the age of 20 to 28 from different faculties and data obtained was analyzed using SPSS 24.0 using mean score, percentage, frequency, and Pearson correlation. Conclusions: The level of stigma towards mental illness is low and insignificant, and participants generally hold a positive attitude towards seeking mental health services. There is a significant positive correlation between the level of stigma and their attitude towards seeking mental health services.
\end{abstract}

\section{Keywords: personal stigma; public stigma; perceived public stigma; attitudes towards professional mental help-seeking.}

\section{Introduction}

Haque (2005) described the ideas of mental illness and mental health in Malaysia based on the religious texts (as cited from Cheng et al, 2018). In Malay culture, it is seen that the strong influence of religion in the culture as one of the compasses which direct the conceptualization that mental disorders result from the act of deserting or neglecting Islamic values. Meanwhile, in Chinese culture, people are keen that any excessive, unbalanced, or undisciplined emotion is the cause of illnesses. For the Chinese, filial piety is the most prioritized value above all and one's self-worth is dignified by the physical and concrete achievements; things that can be seen and acknowledged that one brings to the family (i.e., education, occupation, and monetary gain). Then, the Christians say that true mental health is not attainable in the absence of a right relationship with God.

According to American College Health Association (2015), mental health issues are common and pervasive in college campuses and universities, with approximately $50 \%$ of adults who attend colleges having been diagnosed with mental disorders (Zivin, Eisenberg, Gollust, \& Golberstein, 2009; as cited from Cheng et al, 2018). Nevertheless, it should also be acknowledged that the help-seeking percentage among the students is alarmingly low. In Malaysia, The Ministry of Health Malaysia's statistics revealed a worsening state of mental health problems among Malaysian students, from one in 10 individuals in 2011 to one in five in 2016 (National Health and Morbidity Survey, 2015). Again, similar to the Americans, undergraduates are among the age group susceptible to the risk of developing mental illness, and thus, it should also be given much attention compared to other age groups and stages of life development. Even though the treatment, effectiveness and the knowledge regarding mental health have improved over the past 50 years, there are still a substantial number of people who refuse to seek for professional mental help given their dire circumstances (Corrigan, 2004).

Stigma, according to Corrigan (2004), has been identified as a major barrier to seeking help from mental health professionals. Aside from having to deal with public stigma, individuals who seek psychological help must also overcome self-stigma, which may play an even more crucial and influential role in help-seeking behaviours (Eisenberg et al., 2009; Vogel et al., 2006). Among samples of colleges' students, racially or ethnically diverse college students with a higher level of self-stigma 
are less likely to seek mental help from professionals (Nam et al., 2013; Vogel, Wade, \& Hackler, 2007; as cited from Cheng et al, 2018). Also, researchers have identified that college students who associate the act of seeking help with their self-stigma are more likely to experience anxiety and depression when they think of seeking help (Cheng, McDermott, \& Lopez, 2015; as cited from Cheng et al, 2018).

Public stigma is one of the vital contributors that affect largely on people's attitudes toward seeking psychological help especially among those from Asian cultural backgrounds (Sue, 1994; Ting \& Hwang, 2009; as cited in Nam, \& Lee, 2015). Students seemed to be fearful of the stigma that related to mental health problems and worried that it would be perceived as a sign of shortcoming and deficiency, while also affecting their future career prospects if a mental health diagnosis were to appear on their medical descriptions (Quinn, Wilson, MacIntyre, \& Tinklin, 2009).

The existence of stigma towards mental illness is unavoidable in most cultures. However, it is even more notable in Asians and Asians Americans as compared to White Europeans and Americans (Kleinman, 2004; Fogel \& Ford, 2005; Yang et al., 2007; Hsu et al, 2008). The term 'stigma' is defined by several different uses. 'Public stigma' is known as the negative stereotypes and prejudices that general community and public held about mental illness and individuals diagnosed with mental illness (Corrigan, 2004). 'Personal stigma' is how an individual, by themselves, would see and treat others who may or may not be stigmatized (Pedersen \& Paves, 2014). 'Perceived public stigma' is the beliefs of members of a society about others' perceptions and attitudes toward people with a certain stigmatized group (Reavley \& Jorm, 2011). This stigma towards mental illness has been putting on a prominent barrier against seeking mental health services from professionals and thus, neglecting the treatment beneficial to the patients (Sartorius, 2007; Schomerus \& Angermeyer, 2008).

In a study done by Ilic et al. (2013), they found that some participants reported how they felt as though they were evaluated and judged through the lens and interpretation as someone "mentally ill". Participants also reported experiences of being the topic of gossips, having their friends or dating partners withdrawing and distancing themselves as a reaction to what has been shared about their mental issues, hurtful remarks, and bad jokes about mental illness or psychiatric treatment. The majority of respondents claimed that they experienced the withdrawal from friends, neighbors, and even relatives. Many people with mental health issues never seem to pursue treatment, while with those who did go for professional mental help did not adhere to the course or completing the whole treatment (Corrigan, 2004). According to previous research, this is due to the stigma that is attached to mental illness and people who tried to seek help for their mental issues.

This research examines both personal stigma and perceived public stigma of the participants rather than self-stigma since both the stigma applies to everyone, with or without the participants having mental health problem (Eisenberg et al., 2009) and whether these two stigmas would significantly affect their attitudes towards professional mental help-seeking (one's inclination to reach out for professional mental help if one is having personal crisis or extended mental and psychological distress) (Soorkia, Snelgar, \& Swami, 2011). Positive attitudes towards professional mental help-seeking mean they are more inclined to seek psychological aids from professionals while negative attitudes towards professional mental help-seeking are when a person is unlikely to reach out for psychological help even in the midst of having psychological issues or discomfort (Soorkia, Snelgar, \& Swami, 2011).

There may be other different factors that are halting the people from pursuing mental health services. As yet, few researchers have taken the initiative to investigate the current perceived stigma of undergraduates towards mental illness, their acceptance towards people with mental illness or a history of mental illness, and their attitudes towards seeking mental health services. Also, most of the previous researches that were done focused on barriers to mental health care in Western countries and it is not yet seen on research in Malaysia, and thus, it is not known if the results can be generalized to Malaysia. It is crucial for the level of stigmatization among undergraduates to be clarified because the stigmatization reflects the inner thoughts of themselves on mental illness and also for the people around them. In knowing the current level of stigmatization among the students, the mental health professionals would be able to improvise on what should be done and what had improved this stigmatization phenomenon. Therefore, this current study sought to answer the following questions:

a) Is the level of stigma towards mental illness significant among the participants?

b) What is their attitude (negative/positive) towards seeking mental health services?

c) Do they accept the people with mental illness as 
normal functioning members of society?

d) Is there a significant correlation between the level of stigma towards mental illness and their attitudes towards seeking mental health services?

\section{Methods}

Participants. This research is done in the form of descriptive study. The subjects for the study consisted of a number of 100 undergraduates from a public university in Malaysia from the age of 20 to 28 years old. The subjects were picked randomly from different faculties and were given a brief instruction on how to complete the questionnaires. All of the respondents $(n=100$, response rate $=$ $100 \%$ ) completed the questionnaires independently and the questionnaires were returned to the researcher. Each of the questionnaires consists of three parts and the data obtained was analyzed using SPSS version 24.0.

Measures. Part A: Demography. Part A in the questionnaires includes the items related to the background of the respondents: their age, gender, ethnicity, and faculty of their studies. There are four options related to age: (1) 17 - 20 years old, (2) 21 24 years old, (3) 25 - 28 years old, and (4) 29 years old and above. Next, there are four options regarding their ethnicity: (a) Malay, (b) Chinese, (c) Indian, and (d) others. Meanwhile, there are no options of the faculty of studies given since the respondents are to fill it on their own accord.

Part B: The Perceived Stigma Questionnaire $(\boldsymbol{P S Q})$. In this study, only the modified version of the Discrimination- Devaluation (D-D) Scale containing 12 questions statement from the original PSQ developed by Link in 1989 was used. Only the devaluation-discrimination scale is used since this research is principally concentrated on assessing the attitudes and perceptions of participants toward people who had and are receiving mental health services. In the modified version, the items were rewritten to inquire the participants' thoughts and opinions on what they themselves would do as opposed to what most people out there would do.

To measure people's personal stigma, which is their own stigmatizing attitudes about seeking mental health treatment from professionals, 10 items with "Most people" are replaced with "I." For instance, the original item "Most people would willingly accept a mental health consumer as a close friend' was changed to 'I would willingly accept a person who receives mental health services as a close friend'. Also, to measure the participants' perceived public stigma, 2 items that start with "Most people think . ..", and then followed by a stereotype or a form of discrimination, or a kind of accepting perception or attitude towards people with mental illness diagnosis) were asked.

Participants are asked the extent to which they agree with statements about individuals with mental illness, rated on a six-point Likert scale: strongly disagree $=1$, disagree $=2$, somewhat disagree $=3$, somewhat agree $=4$, agree $=5$, and strongly agree $=6$. Some of the items are reverse scored (i.e. 5, 6, 7, 9, $11,12)$, and scores for all the items are added to obtain a total score ranging from 12 to 72 . Lower scores on the scale indicate more devaluationdiscrimination toward the mentally ill.

Table 1

Reliability and validity of PSQ

\begin{tabular}{ccc}
\hline Instrument & $\begin{array}{c}\text { Cronbach's } \\
\text { alpha }\end{array}$ & $\begin{array}{c}\text { Reliability } \\
\text { coefficients }\end{array}$ \\
\hline PSQ & 0.85 & $0.78-0.87$ \\
\hline
\end{tabular}

Part C: The Inventory of Attitudes toward Seeking Mental Health Services (IASMHS). IASMHS was first developed by Mackenzie, Knox, Gekoski, and Macaulay in 2004. The 24-item scale is created to determine the attitudinal factors that influence the act of seeking mental health services. This scale was developed based on Fisher and Turner's (1970) Attitudes toward Seeking Professional Psychological Help Scale. Results showed that the 24-item scale could be explained and understood in terms of three correlated factors, which makes up for $43 \%$ of variance ( 8 items for each subscale): (a) Psychological openness (PO), (b) Help-seeking propensity (HSP), and (c) Indifference to stigma (IS).

Firstly, psychological openness (PO) refers to the degree to which an individual is open to acknowledging the presence of a psychological problem and to seek professional care for such a problem. Question 1, 4, 7, 9, 12, 14, 18, and 21 belongs to this subscale. Next, the help-seeking propensity (HSP) subscale reflects one's willingness and perceived ability to seek help for psychological problems and comprises question $2,5,8,10,13,15$, 19, and 22. Meanwhile, another 8 questions: 3, 11, $16,17,20,23$, and 24 belongs to the subscale indifference to stigma (IS), where this subscale refers to how concerned an individual would feel if significant others were to discover that they were receiving psychological care (Hyland et al., 2015). Each factor is proposed to be measured via 8 items and each item is measured using a five-point Likertscale ranging from 0 ("disagree") to 4 ("agree"). The following items are reverse scored: $1,3,4,6,7$, $9,11,12,14,16,17,18,20,21,23$, and 24. 
Table 2

Reliability and validity of IASMHS

\begin{tabular}{lcc}
\hline Subscales & Cronbach's alphas & $\begin{array}{c}\text { Test-retest } \\
\text { Reliability }\end{array}$ \\
\hline PO & 0.82 & 0.86 \\
HSP & 0.76 & 0.64 \\
IS & 0.79 & 0.91 \\
\hline
\end{tabular}

$P O=$ Psychological openness, HSP = Help-seeking propensity, IS = Indifference to stigma

\section{Results}

\section{Participants' demographic characteristics}

Among 100 respondents involved in this study, more than half of the sample is made up of female respondents $(70 \%, \mathrm{n}=70)$, while male respondents consist of 30 of them $(30 \%, \mathrm{n}=30)$. Age wise, respondents aged 21 to 24 makes up the largest number of the sample, which is $81(81 \%)$, then 17 to 20 , which is 10 of them (10\%), and $9 \%$ participants from ages 25 to 28 . Then, regarding the ethnicity, a majority of the respondents is made up of Malay undergraduates, which is 44 of them (44\%), followed by Chinese with 36 of them (36\%), the second least number of respondents are the Indians respondents, 17 of them (17\%), and the least number of the respondents are in the 'others', where 2 of them are from Brunei while another female respondent does not specify her ethnicity in the questionnaire.

\section{Level of stigma towards mental illness among the participants}

12 questions from Part B of the questionnaires were analyzed using SPSS 24.0 by utilizing the means score, frequency, and percentage.

From the percentage and means obtained, it can be seen that for the respondents, the level of the stigma towards mental illness and also towards the people who have the mental illness is low and not significant. Besides, it is also seen that the participants generally hold a positive and nonstigmatizing attitude towards people with mental illness, and those who had, or are receiving mental health services. Also, it shows that most of the participants are generally inclined towards acceptance of the people with mental illness as normal functioning members of society. Perceived public stigma seems to hold a higher percentage and greater level of stigmatizing attitudes as compared to personal stigma. This means that the participants may have overestimated the negativity of the stigma that they perceive the public may hold against people with mental illness diagnosis as compared to their own personal stigma attitudes.
Table 3

Perceptions of respondents towards people with mental illness (percentage, frequency, means and standard deviation)

\begin{tabular}{|c|c|c|c|c|c|}
\hline Item & $\begin{array}{l}\text { Some- } \\
\text { what } \\
\text { agree } \\
(\%)\end{array}$ & Agree (\%) & $\begin{array}{l}\text { Strong- } \\
\text { ly agree } \\
(\%)\end{array}$ & Means & SD \\
\hline 1 & $37(37 \%)$ & $34(34 \%)$ & $17(17 \%)$ & 4.54 & 0.968 \\
\hline 2 & $25(25 \%)$ & $30(30 \%)$ & $14(14 \%)$ & 4.18 & 1.209 \\
\hline 3 & $33(33 \%)$ & $28(28 \%)$ & $1(1 \%)$ & 4.13 & 1.143 \\
\hline 4 & $38(38 \%)$ & $29(29 \%)$ & $9(9 \%)$ & 4.08 & 1.203 \\
\hline 5 & $11(11 \%)$ & $8(8 \%)$ & $2(2 \%)$ & 4.46 & 1.298 \\
\hline 6 & $22(22 \%)$ & $19(19 \%)$ & $9(9 \%)$ & 3.43 & 1.394 \\
\hline 7 & $32(32 \%)$ & $8(8 \%)$ & $5(5 \%)$ & 3.83 & 1.349 \\
\hline 8 & $42(42 \%)$ & $24(24 \%)$ & $10(10 \%)$ & 4.09 & 1.129 \\
\hline 9 & $27(27 \%)$ & $13(13 \%)$ & $1(1 \%)$ & 3.76 & 1.147 \\
\hline 10 & $34(34 \%)$ & $12(12 \%)$ & $8(8 \%)$ & 3.57 & 1.273 \\
\hline 11 & $30(30 \%)$ & $19(19 \%)$ & $10(10 \%)$ & 3.16 & 1.212 \\
\hline 2 & $22(22 \%)$ & $8(8 \%)$ & $3(3 \%)$ & 4.09 & 1.295 \\
\hline
\end{tabular}

$1=$ Accept one as close friend; $2=$ One is as intelligent as average person; 3 = One is as trustworthy as average person; 4 = Accept one as teacher for young children in public school; 5 = Entering mental hospital is a personal failure; $6=$ Refusal of allowing one to take care of their children even if he/she has been well; 7 = Being in a mental hospital makes one lesser than an average person; $8=$ Acceptance of hiring one to work if qualified; $9=$ Refusal of consideration the application of one and prefer another applicant; $10=$ Most people treat person who receives mental health services as anyone else; $11=$ Reluctance of young people to date one; $12=$ One's opinion will be taken less seriously.

\section{Attitude (negative/positive) towards seeking mental health services}

24 questions from Part $\mathrm{C}$ of the questionnaires were analyzed using SPSS 24.0 by utilizing the means score, frequency, and percentage.

Table 4

Mean and Standard Deviation for subscale HelpSeeking Propensity (HSP)

\begin{tabular}{lccc}
\hline Item & Mean & SD & $\begin{array}{c}\text { Sequences among 12 } \\
\text { questions }\end{array}$ \\
\hline 2 & 2.73 & 0.983 & 3 \\
5 & 2.92 & 0.813 & 2 \\
8 & 2.71 & 0.988 & 4 \\
10 & 3.00 & 0.865 & 1 \\
13 & 2.36 & 1.133 & 8 \\
15 & 2.66 & 0.966 & 5 \\
19 & 2.46 & 0.937 & 7 \\
22 & 2.66 & 0.945 & 6 \\
Total & $\mathbf{2 1 . 5}$ & $\mathbf{7 . 6 3}$ &
\end{tabular}

$2=$ Knowing of what to do and talk if decided to seek help for psychological problems; $5=$ Would recommend good friends to seek mental services if they ask; $8=$ Is confident to find relief in psychotherapy; $10=$ Could get professional help if wanted to; $13=$ It is easy to find the time to see professional for mental services; $15=$ Would want to get professional help if were worried or upset for some time; $19=$ Inclined to get professional attention if having mental breakdown; $22=$ Willingly confide intimate matters to person if one might help 
From Table 4 above, it can be seen that the total mean for the subscale of Help-Seeking Propensity is 21.5 over the total mean for three subscales, 51.03. $($ Psychological openness $(\mathrm{PO})=12.84$; Indifference to stigma (IS) $=16.69$ ). This shows that the respondents have a positive attitude towards seeking mental health services since the help-seeking propensity (HSP) subscale reflects one's willingness and perceived ability to seek help for psychological problems.

Table 5

Overall Mean Score and Standard Deviation for three subscales of IASMHS

\begin{tabular}{lcc}
\hline \multicolumn{1}{c}{ Subscales } & Mean & SD \\
\hline HSP & 21.5 & 7.63 \\
PO & 12.84 & 9.26 \\
IS & 16.69 & 9.213 \\
Total & $\mathbf{5 1 . 0 3}$ & $\mathbf{2 6 . 1 0 3}$ \\
\hline PO = Psychological openness, HSP & $=$ Help-seeking \\
propensity, IS = Indifference to stigma & \\
\hline
\end{tabular}

\section{Correlation between the Level of Stigma Towards Mental Illness and Attitudes Towards Seeking Mental Health Services}

To analyze the relationship between the level of stigma towards mental illness and their attitudes towards seeking mental health services, Pearson R correlation is used.

Table 6

Correlation between the Level of Stigma Towards Mental Illness and Attitudes Towards Seeking Mental Health Services

\begin{tabular}{|c|c|c|c|}
\hline & & $\begin{array}{l}\text { Level of } \\
\text { Stigma } \\
\text { Towards } \\
\text { Mental } \\
\text { Illness }\end{array}$ & $\begin{array}{l}\text { Attitudes } \\
\text { Towards } \\
\text { Seeking } \\
\text { Mental } \\
\text { Health } \\
\text { Services }\end{array}$ \\
\hline $\begin{array}{l}\text { Level of } \\
\text { Stigma } \\
\text { Towards } \\
\text { Mental } \\
\text { Illness }\end{array}$ & $\begin{array}{l}\text { Pearson } \\
\text { Correlation } \\
\text { Sig (2-tailed) } \\
\mathrm{N}\end{array}$ & 100 & $\begin{array}{r}0.000 \\
100\end{array}$ \\
\hline $\begin{array}{l}\text { Attitudes } \\
\text { Towards } \\
\text { Seeking } \\
\text { Mental } \\
\text { Health } \\
\text { Services }\end{array}$ & $\begin{array}{l}\text { Pearson } \\
\text { Correlation } \\
\text { Sig (2-tailed) }\end{array}$ & $\begin{array}{l}0.419 \\
0.000\end{array}$ & 100 \\
\hline
\end{tabular}

The correlation between perceived stigmatization towards mental illness and attitudes towards seeking mental health services is $r=0.419$ ( $\mathrm{p}<0.05)$. It is concluded that there is a significant positive correlation between perceived stigmatization towards mental illness and attitudes towards seeking mental health services among the participants. Hence, the hypothesis is accepted.

\section{Discussion and Conclusion}

The present study revealed that the level of stigma is low among the participants and it significantly affects their positive attitudes towards seeking mental health services. Contrary to expectation and comparison with previous research, the finding in this study shows that the respondents are showing a positive attitude towards seeking mental health services (one's willingness and perceived ability to seek help for psychological problems). However, it is similar to a study done by Chen and Chang (2016) on the staffs in a psychiatric hospital in Taiwan which shows that they do have a positive attitude towards people with mental illness in general situation. Besides, in a study done by Gateshill, Kucharska-Pietura, and Wattis in 2010, they found that the attitudes of both mental health professionals and non-mental health professionals towards people with eating disorders were deemed positive, in which also reported them feeling sympathy towards individuals with eating disorders.

Nevertheless, there are also limitations to the study. First, the researcher examined the participants' personal stigma by obtaining the data from questionnaires on how one would hypothetically treat or view someone with mental illness diagnosis. The researcher has no means of knowing if the participants would actually react in such a way that is being examined in the questionnaires when they meet individuals with mental illness diagnosis. While this option gives participants the freedom to express an option where they may not have a firm opinion, it somewhat limits our understanding of how individuals would genuinely and realistically view others (or perceive to be viewed by others).

The participants may consciously or unconsciously understate their explicit and implicit levels of personal stigma because they were more inclined to show a pleasant and socially favorable attitude towards individuals with mental illness diagnosis. Secondly, since there are only 100 participants in this study, and not to mention that they have a similar educational background, which in this context means they are pursuing tertiary education in a public university in Malaysia, the findings obtained from this study may not adequately generalize the result to other sociodemographic groups. Therefore, a comparison between previous studies from other countries, populations, and sociodemographic factors may not be sufficiently discussed. 


\section{Acknowledgements}

First and foremost, I am utmost thankful to my supervisor, Dr. Noor Aishah binti Rosli for guiding me throughout the process of completing my thesis and giving her time discussing the progress despite of her busy schedule. My parents, Hong Tek Yong and Wong Siew Kee for offering a great support and encouragement during the period of completing my thesis, and definitely, in the past, present and the future to come. Finally, to the friends who have been sharing their advice and opinions on how to progress with my thesis: Wan Jing Mun, Farhana Nabila binti Fakarrudin, Chong Pei Ying, Jennifer Ung, and Hoi Kah Mun. I am deeply thankful and words are never enough.

\section{References}

Ali, K., Farrer, L., Fassnacht, D. B., Gulliver, A., Bauer, S., \& Griffiths, K. M. (2017). Perceived barriers and facilitators towards help-seeking for eating disorders: A systematic review. International Journal Of Eating Disorders, 50(1), 9-21.

Angermeyer, M. C., Schulze, B., \& Dietrich, S. (2003). Courtesy stigma. Social Psychiatry \& Psychiatric Epidemiology, 38(10), 593.

Arboleda-Florez, J., \& Stuart, H. (2012). From sin to science: Fighting the stigmatization of mental illness. Canadian Journal of Psychiatry, 57(8), 457-463.

Armando, M., Nelson, B., \& Yung, A. R. et al. (2010). Psychotic-like experiences and correlation with distress and depressive symptoms in a community sample of adolescents and young adults. Schizophr Res, 119(1-3), 258-265.

Aromaa. E, Tolvanen. A, \& Tuulari, J. et al. (2011). Predictors of stigmatizing attitudes towards people with mental disorders in a general population in Finland. Nord $J$ Psychiatry, 65(2), 125-132.

Aromaa, E. (2011). Attitudes Towards People with Mental Disorders in a General Population in Finland (Doctoral dissertation). Retrieved from https://jyx.jyu.fi/dspace/bitstream/handle/123456789/37001 /978-952-245-525-3.pdf?sequence $=1$

Beavan, V., Read, J., \& Cartwright, C. (2011). The prevalence of voice hearers in the general population: a literature review. J Ment Health, 20(3), 281-292.

Bernburg, J. G. (2009). Labeling theory. In: Krohn, M. D., Lizotte, A., \& Hall, G. P (Eds.), Handbook on Crime and Deviance (pp187-207). Springer Science + Business Media.

Byrne, P. (2000). Stigma of mental illness and ways of diminishing it. Advances in Psychiatric Treatment, 6, 65-72.

Chen, M. D., \& Chang, Y. C. (2016). Personnel attitudes toward people with mental illness at a psychiatric hospital in Taiwan. International Journal of Social Psychiatry, 62(4), $361-368$.

Cheng, H., Wang, C., McDermott, R. C., Kridel, M., \& Rislin, J. L. (2018). Self-Stigma, Mental Health Literacy, and Attitudes Toward Seeking Psychological Help. Journal of Counseling \& Development, 96(1), 64-74.

Chui, A. Y. T. (2015). Cross-sectional Survey: Public Attitude toward Mental Illness in China. Int Arch Nurs Health Care, 1:025.

Chong, S. A., Verma, S., Vaingankar, J. A et al. (2007). Perception of the public towards the mentally ill in developed Asian country. Soc Psychiatry Psychiatr Epidemiol, 42(9), 734-739.

Corrigan, P. W. (2004). How stigma interferes with mental health care. American Psychologist, 59, 614-625. http://doi.org/cpxspn

Corrigan, P. W., Morris, S., Larson, J., Rafacz, J., Wassel, A., Michaels, J., ... Ru" sch, N. (2010). SELF-STIGMA AND COMING OUT ABOUT ONE'S MENTAL ILLNESS. JOURNAL OF COMMUNITY PSYCHOLOGY, 38(3), 259275.

Coppens, E., Van Audenhove, C., Scheerder, G., Arensmanb, E., Coffey, C., \& Costa, S. et al. (2013). Public attitudes toward depression and help-seeking in four European countries baseline survey prior to the OSPI-Europe intervention. Journal of Affective Disorders, 150(2), 320-329.

Crossman, A. (2017, March 2). Stigma: Notes on the Management of Spoiled Identity. Retrieved from https://www.thoughtco.com/stigma-notes-on-themanagement-of-spoiled-identity-3026757

Davey, C. L. G. (2013, August 20). Mental Health \& Stigma. Retrieved from https://www.psychologytoday.com/blog/why-weworry/201308/mental-health-stigma

Erving Goffman's Face and Stigma Theory Explained. (2017, January 9). Retrieved 5 July 2017, from http://healthresearchfunding.org/erving-goffmans-face-andstigma-theory-explained/

Eisenberg, D., Downs, M. F., Golberstein, E., \& Zivin, K. (2009). Stigma and help-seeking for mental health among college students. Medical Care Research and Review, 66, 522-541. http://doi.org/c62t37

Fernando, S. M. (2010). Stigma and discrimination toward people with mental illness in Sri Lanka (Doctoral dissertation). Available from Digital Theses @ UOW.

Fogel, J. \& Ford, D. E. (2005). Stigma beliefs of Asian American with depression in an Internet sample. Can $\mathrm{J}$ Psychiatry 50(8):470-477

Fuller, M., Healey, M., Bradley, A., \& Hall, T. (2004). Barriers to learning: a systematic study of the experience of disabled students in one university. Studies In Higher Education, 29(3), 303-318.

Gangi, C. E., Yuen, E. K., Levine, H., \& McNally, E. (2016). Hide or Seek? The Effect of Causal and Treatability Information on Stigma and Willingness to Seek Psychological Help. Journal of Social \& Clinical Psychology, 35(6), 510-524.

Gateshill, G., Kucharska-Pietura, K., \& Wattis, J. (2011). Attitudes towards mental disorders and emotional empathy in mental health and other healthcare professionals. The Psychiatrist, 35, 101-105. doi: 10.1192/pb.bp.110.029900

Goffman, E. (1963). Stigma: Notes on the Management of Spoiled Identity. New Jersey, USA: Prentice-Hall Inc.

Golberstein. E, Eisenberg. D, Gollust, S. E. (2008). Perceived stigma and mental health care seeking. Psychiatr Serv, 59(4), 392-399.

Griffiths, K. M., Christensen, H., Jorm, A. F., Evans, K., \& Groves, C. (2004). Effect of Web-based depression literacy and cognitive-behavioural therapy interventions on stigmatising attitudes to depression: Randomised controlled trial. British Journal of Psychiatry, 185, 342-349.

Hamilton, S., Lewis-Holmes, E., Pinfold, V., Henderson, C., Rose, D., \& Thornicroft, G. (2014). Discrimination against people with a mental health diagnosis: qualitative analysis of reported experiences. Journal Of Mental Health, 23(2), 88-93. 
Henderson, C., Evans-Lacko, S., \& Thornicroft, G. (2013). Mental Illness Stigma, Help Seeking, and Public Health Programs. American Journal Of Public Health, 103(5), 777780 .

Hyland, P., Boduszek, D., Dhingra, K., Shevlin, M., Maguire, R., \& Morley, K. (2015). A Test of the Inventory of Attitudes toward Seeking Mental Health Services. British Journal of Guidance and Counselling, 43 (4).

Hsu, L. K. G., Wan, Y. M., Chang, H. et al. (2008). Stigma of depression is more severe in Chinese American than Caucasian Americans. Psychiatry 71(3):210-218

Ilic, M., Reinecke, J., Bohner, G., Röttgers, H., Beblo, T., Driessen, M., \& ... Corrigan, P. W. (2013). Belittled, Avoided, Ignored, Denied: Assessing Forms and Consequences of Stigma Experiences of People With Mental Illness. Basic \& Applied Social Psychology, 35(1), $31-40$

Ilic, N., Henderson, H., Henderson, C., Evans-Lacko, S., \& Thornicroft, G. (2014). Attitudes towards mental illness. Retrieved from http://healthsurvey.hscic.gov.uk/supportguidance/public-health/health-survey-for-england2014/attitudes-towards-mental-illness.aspx

Ikeme, C. (2012). THE STIGMA OF A MENTAL ILLNESS LABEL: ATTITUDES TOWARDS INDIVIDUALS WITH MENTAL ILLNESS. (Unpublished master's thesis). University of Dayton, Ohio.

Karnieli-Miller, O., Perlick, D. A., Nelson, A., Mattias, K., Corrigan, P., \& Roe, D. (2013). Family members' of persons living with a serious mental illness: Experiences and efforts to cope with stigma. Journal of Mental Health, 22(3), 254-262.

Kleinman, A. (2004). Culture and depression. N Engl J Med, 351(10), 951-953.

Komiti, A., Judd, F., \& Jackson, H. (2006). The influence of stigma and attitudes on seeking help from a GP for mental health problems. Social Psychiatry \& Psychiatric Epidemiology, 41(9), 738-745.

Lam, T. P. \& Sun, K. S. (2014). Stigmatizing opinions of Chinese toward different

types of mental illnesses: a qualitative study in Hong Kong. Int J Psychiatry Med, 48, 217-228.

Larkings, J. S., Brown, P. M., \& Scholz, B. (2017). "Why am I like this?" Consumers discuss their causal beliefs and stigma. International Journal Of Mental Health, 46(3), 206226 .

LeBell, T. (2008). Perceptions of and responses to stigma. Sociology Compass, 2, 409-432.

Lee, S., Lee, M. T., Chiu, M. Y., \& Kleinman, A. (2005). Experience of social stigma by people with schizophrenia in Hong Kong. Br J Psychiatry, 186, 153-157.

Lien, Y., Kao, Y., Liu, Y., Chang, H., Tzeng, N., Lu, C., \& ... Loh, C. (2015). Relationships of perceived public stigma of mental illness and psychosis-like experiences in a nonclinical population sample. Social Psychiatry \& Psychiatric Epidemiology, 50(2), 289-298.

Link BG, Struening EL, \& Neese-Todd S et al. (2001). Stigma as a barrier to recovery: the consequences of stigma for the self-esteem of people with mental illnesses. Psychiatr Serv, 52(12), 1621-1626.

Link, B. G., \& Phelan, J. C. (2006). Stigma and its public health implications. Lancet, 367(9509), 528-529.

Liu, J., Yan, F., Ma, X., Guo, H., Tang, Y., Rakofsky, J., \& ... Rakofsky, J. J. (2016). Perceptions of public attitudes towards persons with mental illness in Beijing, China: results from a representative survey. Social Psychiatry \& Psychiatric Epidemiology, 51(3), 443-453.

Mackenzie, C. S., Knox, V. J., Gekoski, W. L., \& Macaulay, H. L. (2004). An adaptation and extension of the attitudes towards seeking professional psychological help scale. Journal of Applied Social Psychology, 34(11), 2410-2435.

Mackenzie, C. S., Erickson, J., Deane, F. P., \& Wright, M. (2014). Changes in attitudes toward seeking mental health services: A 40-year cross-temporal meta-analysis. Clinical Psychology Review, 34, 99 - 106.

McClure, A. K. (2010). Willingness of Individuals to Seek Mental Health Treatment: The Impact of Gender and Parent Therapy Experience (Master's thesis). Retrieved from http://digitalcommons.wku.edu/theses/187

Meier, A., Csiernik, R., Warner, L., \& Forchuk, C. (2015). The Stigma Scale: A Canadian Perspective. Social Work Research, 39(4), 213-222.

Mingus, W. \& Burchfield, K. B. (2012): From prison to integration: applying modified labeling theory to sex offenders. Criminal Justice Studies: A Critical Journal of Crime, Law and Society, 25(1), 97-109.

Ministry of Health Malaysia. (2015). National Health and Morbidity Survey, Volume II: Non-Communicable Diseases, Risk Factors \& Other Health Problems. Retrieved from http://www.iku.gov.my/images/IKU/Document/REPORT/n hmsreport2015vol2.pdf

Mishra, S. I., Lucksted, A., Gioia, D., Barnet, B., \& Baquet, C. R. (2009). Needs and Preferences for Receiving Mental Health Information in an African American Focus Group Sample. Community Mental Health Journal, 45(2), 117-126. http://doi.org/10.1007/s10597-008-9157-4

Mojtabai, R. (2007). Americans' attitudes toward mental health treatment seeking: $1990-2003$. Psychiatric Services, 58, $642-651$.

n.a. (2016. Julv 1). More Malavsians expected to suffer from mental illness by 2020. The Star Online. Retrieved from https://www.thestar.com.my/news/ nation/2016/07/01/more-malaysians-expected-to-sufferfrom-mental-illness-by-2020/\#AOsLw6cYOi7TbDoh.99

Nam, S. K., \& Lee, S. M., (2015). The Role of Attachment and Stigma in the Relationship Between Stress and Attitudes Toward Counseling in South Korea. Journal of Counseling \& Development, 93, 212-224.

NHS Information Centre. (2011). Attitudes to Mental Illness 2011 survey report. Retrieved from https://www.google.com/url?sa=t\&rct=j\&q=\&esrc=s\&sourc $\mathrm{e}=$ web $\& \mathrm{~cd}=6 \& \mathrm{cad}=\mathrm{rja} \& u a c t=8 \& \mathrm{ved}=0 \mathrm{ahUKEwimiN} 7 \mathrm{~V} 2 \mathrm{~b}$ fVAhWDm5QKHWzVCR8QFghQMAU\&url=http $\% 3 \mathrm{~A} \% 2$ F\%2Fcontent.digital.nhs.uk\%2Fcatalogue\%2FPUB00292\% 2Fatti-ment-illn-2011-sur-rep.pdf\&usg= AFQjCNFeUWSIfECoeYGMjgcehfqExj7p_w

Perez, C. (2014, July 1). Revisiting Erving Goffman's Stigma: Notes on the Management of Spoiled Identity by Cristina Perez. Retrieved from https://sahncambridge.wordpress.com/2014/07/01/revisiting -erving-goffmans-stigma-notes-on-the-management-ofspoiled-identity-by-cristina-perez/

Pedersen, E. R. \& Paves, A. P. (2014). Comparing perceived public stigma and personal stigma of mental health treatment seeking in a young adult sample. Psychiatry Res, 219(1), 143-150.

Quinn, N., Wilson, A., MacIntyre, G., \& Tinklin, T. (2009). People look at you differently: students' experience of mental health support within Higher Education. British Journal of Guidance \& Counselling, 37(4), 405-418. http://dx.doi.org/10.1080/03069880903161385 
Reavley, N. J. \& Jorm, A. F. (2011) Young people's stigmatizing attitudes towards people with mental disorders: findings from an Australian national survey. Aust $N \mathrm{Z} \mathrm{J}$ Psychiatry, 45(12), 1033-1039.

Reynders, A., Kerkhof, A., Molenberghs, G., \& Audenhove, C. (2014). Attitudes and stigma in relation to help-seeking intentions for psychological problems in low and high suicide rate regions. Social Psychiatry \& Psychiatric Epidemiology, 49(2), 231-239.

Rusch N, Corrigan PW, \& Wassel A et al. (2009). A stresscoping model of mental illness stigma: I. Predictors of cognitive stress appraisal. Schizophr Res, 110(1-3), 59-64.

Rusch, N., Todd, A. R., Bodenhausen, G. V., \& Corrigan, P. W. (2010). Do people with mental illness deserve what they get? Links between meritocratic worldviews and implicit versus explicit stigma. European Archives of Psychiatry and Clinical Neuroscience, 260, 617 - 625. http://doi.org/d6463m

Rüsch, N., Brohan, E., Gabbidon, J., Thornicroft, G., \& Clement, S. (2014). Stigma and disclosing one's mental illness to family and friends. 49(7), 1157-1160.

Sartorius, N. (2007). Stigma and mental health. Lancet, $370(9590), 810-811$.

Schomerus, G. \& Angermeyer, M. C. (2008). Stigma and its impact on help-seeking for mental disorder: what do we know? Epidemiol Psychiatr Soc, 17(1), 31-37.

Schomerus, G., Matschinger, H., \& Angermeyer, M. C. (2009). The stigma of psychiatric treatment and help-seeking intentions for depression. European Archives Of Psychiatry \& Clinical Neuroscience, 259(5), 298-306.

Schulze, B. (2007). Stigma and mental health professionals: A review of the evidence on an intricate relationship. International Review Of Psychiatry, 19(2), 137-155.

Soorkia, R., Snelgar, R., \& Swami, V. (2011). Factors influencing attitudes towards seeking professional psychological help among South Asian students in Britain. Mental Health, Religion \& Culture, 14(6), 613-623.

Stickney. S, Yanosky. D, Black, D. R et al. (2012). Sociodemographic variables and perceptual moderators related to mental health stigma. J Ment Health, 21(3), 244-256.

Stanghellini, G., Langer, A. I., Ambrosini, A., \& Cangas, A. J. (2012). Quality of hallucinatory experiences: differences between a clinical and a non-clinical sample. World Psychiatry, 11(2), 110-113.

Tang, T. T.-T., Reilly, J., Dickson, J. M. (2012). Attitudes toward seeking professional psychological help among Chinese students at a UK university. Counselling and

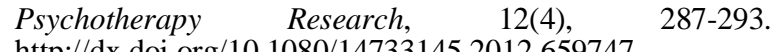
http://dx.doi.org/10.1080/14733145.2012.659747

Taylor Nelson Sofres \& British Market Research Bureau. (2014). Attitudes to Mental Illness 2014 Research Report: Prepared for Time to Change

The evolving understanding of stigma. (2010). Harvard Mental Health Letter, 27(1), 6.

The Hong Kong Council of Social Service. (2011). The Difficulties in Integrated_Community Centre. Hong Kong.

Topkaya, N., Vogel, D. L., \& Brenner, R. E. (2017). Examination of the Stigmas Toward Help Seeking Among Turkish College Students. Journal of Counseling \& Development, 95(2), 213-225.

Tsang, H. W. H., Tam, P. K. C., Chan, F., \& Cheung, W. M. (2003). Stigmatizing attitudes towards individuals with mental illness in Hong Kong: Implication for their recovery. J Community Psychol, 31, 383-396.

Van Brakel, W.H., Anderson, A.M., Mutatkar, R.K., Bakirtzief, Z., Nicholls, P.G., Raju M.S., \& Das-Pattanayak, R.K. (2006). The Participation Scale: measuring a key concept in public health. Disability and Rehabilitation, 28, 193- 203.

Victoria University of Wellington. (n.d.). Self-stigma. Retrieved from

https://www.mentalhealth.org.nz/assets/ResourceFinder/indi vidual-self-stigma-resource-card-4.pdf

Wang, X., Peng, S., Li, H., \& Peng, Y. (2015). How depression stigma affects attitude toward help seeking: The mediating effect of depression somatization. Social Behavior and Personality: An international journal, 43, 945-954. https://doi.org/10.2224/sbp.2015.43.6.945

Wrigley, S., Jackson, H., Judd, F., \& Komiti, A. (2005). The role of stigma and attitudes towards help-seeking from a GP for mental health problems in a rural town. Aust $N Z J$ Psychiatry, 39, 514-521.

World Health Organization. (2001). The world health report 2001: mental health-new understanding, new hope. WHO, Geneva.

Yang, L., Kleinman, A., \& Link, B. et al. (2007). Culture and stigma: adding moral experiences to stigma theory. Soc Sci Med, 64(1), 1524-1535.

Yang, L. H. (2007). Application of stigma theory to Chinese groups with mental illness: synthesis and new directions. Singap Med J, 48(11), 977-985.

Yang, L. H., Phillips, M. R., \& Lo, G. et al. (2010). “Excessive thinking", as explanatory models for schizophrenia: impacts on stigma and "moral" status in Mainland China. Schizophr Bull, 36(4), 836-845. 